\title{
The Association Between Preoperative Pain Catastrophizing and Chronic Pain After Hysterectomy - Secondary Analysis of a Prospective Cohort Study
}

This article was published in the following Dove Press journal:

Journal of Pain Research

\author{
Hon Sen Tan' \\ Rehena Sultana ${ }^{2}$ \\ Nian-Lin Reena $\mathrm{Han}^{3}$ \\ Chin Wen Tan (D) ${ }^{1,4}$ \\ Alex Tiong Heng Sia ${ }^{1,4}$ \\ Ban Leong Sng ${ }^{1,4}$ \\ 'Department of Women's Anaesthesia, \\ KK Women's and Children's Hospital, \\ Singapore; ${ }^{2}$ Centre for Quantitative \\ Medicine, Duke-NUS Medical School, \\ Singapore; ${ }^{3}$ Division of Clinical Support \\ Services, KK Women's and Children's \\ Hospital, Singapore; ${ }^{4}$ Anesthesiology and \\ Perioperative Sciences Academic Clinical \\ Program, SingHealth-Duke-NUS Medical \\ School, Singapore
}

Purpose: Hysterectomy is associated with a high incidence of chronic post-hysterectomy pain (CPHP). Pain catastrophizing, a negative cognitive-affective response to pain, is associated with various pain disorders but its role in CPHP is unclear. We aimed to determine the association of high preoperative pain catastrophizing with CPHP development and functional impairment 4 months after surgery.

Patients and Methods: Secondary analysis of a prospective cohort study of women undergoing abdominal/laparoscopic hysterectomy to investigate the association between high pain catastrophizing (pain catastrophizing scale, PCS $\geq 20$ ) with CPHP and associated functional impairment (defined as impairment with standing for $\geq 30$ minutes, sitting for $\geq 30$ minutes, or walking up or down stairs). CPHP and functional impairment were assessed via 4- and 6-month phone surveys.

Results: Of 216 patients, $72(33.3 \%)$ had high PCS, with mean (SD) of 30.0 (7.9). In contrast, 144 (66.7\%) patients had low PCS, with mean (SD) of 9.0 (4.7). At 4 months, 26/63 (41.3\%) patients in the high PCS group developed CPHP, compared to $24 / 109(22.0 \%)$ in the low PCS group. At 6 months, 14/53 (26.4\%) high PCS patients developed CPHP, compared to $10 / 97(10.3 \%)$ patients with low PCS. High PCS was independently associated with CPHP at 4 months (OR 2.49 [95\% CI 1.27 to 4.89], $\mathrm{p}=0.0082$ ) and 6 months (OR 3.12 [95\% CI 1.28 to 7.64$], \mathrm{p}=0.0126$ ) but was not associated with functional impairment. High $\mathrm{PCS} \geq 20$, presence of evoked mechanical temporal summation (MTS), and history of abdominal/pelvic surgery predict CPHP at 4 months with area under the curve (AUC) of 0.69. Similarly, $\mathrm{PCS} \geq 20$ and increasing MTS magnitude predicted CPHP at 6 months with AUC of 0.76 .

Conclusion: High PCS was independently associated with CPHP. Future studies should identify other CPHP associated factors to formulate a risk-prediction model and investigate the effectiveness of early intervention for pain catastrophizers in improving pain-related outcomes.

Keywords: pain catastrophizing scale, mechanical temporal summation

\section{Introduction}

Chronic post-surgical pain (CPSP) is defined as pain developing or increasing after a surgical procedure that is localized to the surgical site, and lasts at least 3 months with other possible causes excluded. ${ }^{1}$ CPHP has an estimated incidence of up to $60 \%$ for high-risk procedures. ${ }^{2}$ Patients undergoing hysterectomy are at particularly high risk, with a global incidence of chronic post-hysterectomy pain (CPHP) of
Correspondence: Ban Leong Sng

Department of Women's Anaesthesia, KK

Women's and Children's Hospital, 100

Bukit Timah Road 229899, Singapore

Tel +6563941077

Email sng.ban.leong@singhealth.com.sg
Journal of Pain Research 2020:13 2151-2162 
$14 \%$ to $50 \%{ }^{3}$ In Singapore, hysterectomy for benign indications is associated with $32 \%$ risk of $\mathrm{CPHP}^{4}$ With more than 600,000 hysterectomies performed annually in the USA alone, ${ }^{5}$ the combination of large surgical numbers and high CPHP incidence results in significant adverse impact on health-related quality of life and socioeconomic burden. ${ }^{6}$

The pathogenesis of CPHP involves a complex interplay of psychological and pain vulnerability, genetic predisposition, and sociodemographic factors. ${ }^{7}$ In particular, an element of psychological vulnerability called catastrophizing has been associated with poor pain-related outcomes. ${ }^{8}$ Pain catastrophizing is defined as a negative cognitive-affective response to anticipated or actual pain, and is a multidimensional concept comprising elements of rumination, magnification, and helplessness. ${ }^{9-11}$ The presence of catastrophizing has been associated with multiple pain etiologies including osteoarthritis, ${ }^{12}$ fibromyalgia, ${ }^{13}$ endometriosis, ${ }^{14}$ neuropathic pain, $^{15}$ post-surgical pain, ${ }^{16-18}$ and development of CPHP. $^{4,19}$ Furthermore, catastrophizing may contribute to the development of affective disorders, pain-related disability, and poor response to pain interventions. ${ }^{12,15,17,19-27}$

Several assessments have been developed to quantify pain catastrophizing, of which the most commonly used is the Pain Catastrophizing Scale (PCS) by Sullivan et al. ${ }^{10}$ The PCS was found to have high internal consistency $($ Cronbach alpha $=0.87),{ }^{9,10}$ with a threshold of above 20 to 24 reported to be clinically meaningful for poor pain outcomes and disability. ${ }^{28-30}$ Moreover, unlike other assessments such as the Revised Coping Strategies Questionnaire (CSQ-R), ${ }^{31}$ the PCS has greater specificity for pain catastrophizing ${ }^{9}$ and assesses specific elements of the catastrophizing construct such as rumination, helplessness, and magnification. ${ }^{10}$

In addition to its potential role as a risk-prediction modality for CPHP, preoperative identification of catastrophizing may facilitate interventions such as physical and psychosocial therapy. These interventions have been shown to be effective in treating catastrophizing; Sullivan et al reported a $43 \%$ reduction in catastrophizing, using exercise and psychosocial intervention by occupational and physiotherapists. ${ }^{29}$ Notably, earlier intervention resulted in 39\% reduction in catastrophizing during the subacute period, compared to only $10 \%$ reduction if treatment was delayed over 6 months, ${ }^{32}$ thus highlighting the importance of early risk-assessment and intervention, especially since the reduction of catastrophizing may forestall CPHP development and improve pain-related outcomes. $^{33,34}$

In our previous study, we identified several factors associated with the development of CPHP, and reported that patients with CPHP had significantly higher PCS scores (mean (SD) PCS 20.0 (12.20)) compared to 14.9 (11.64) in patients who did not develop CPHP. ${ }^{4}$ However, the association of high preoperative PCS scores with CPHP development has not been fully elucidated, hence this secondary analysis of patients undergoing abdominal or laparoscopic hysterectomy was performed with two objectives. First, preoperative catastrophizing was assessed using the PCS, and the association between high PCS scores (PCS $\geq 20$ ) and the development of CPHP was determined. Our second objective was to investigate the association of high preoperative PCS scores with painrelated functional impairment of activities such as standing, sitting, and stair-climbing. Additionally, we investigated the associations between preoperative anxiety (assessed using the State-Trait Anxiety Inventory, STAI), mechanical temporal summation (MTS), and tonic heat stimulation with CPHP development.

\section{Patients and Methods}

This is a post-hoc secondary analysis of data collected in a prospective cohort study assessing factors associated with CPHP development. ${ }^{4}$ The study is in accordance with the Declaration of Helsinki, was approved by SingHealth Centralized Institutional Review Board (CIRB ref 2013/ 512/D), and registered at clinicaltrials.gov (NCT02025153). Informed written consent was obtained from all participants. The inclusion criteria were women undergoing scheduled abdominal or laparoscopic hysterectomy for benign indications (eg, fibroids, adenomyosis) at KK Women's and Children's Hospital, Singapore from 2013 to 2017, between 21 and 70 years of age, and American Society of Anesthesiologists (ASA) physical status 1 and 2. Patients undergoing vaginal hysterectomy, with gynecological conditions such as uterine prolapse, endometriosis, malignant disease, chronic pelvic pain, or with preoperative chronic pain or opioid use were excluded.

After enrolment in the study, demographic and medical data were recorded, and patients were asked to complete the PCS preoperatively. The PCS consists of 13 items assessing three components of catastrophizing; rumination, magnification, and helplessness on a five-point scale. ${ }^{10}$ In this study, the threshold for clinically-meaningful PCS scores was set at $P C S \geq 20$, with our study cohort classified 
as $\mathrm{PCS} \geq 20$ (referred as "high PCS"), and $\mathrm{PCS}<20$ (referred as "low PCS"). The threshold of PCS $\geq 20$ was selected based on our previous finding that patients who developed CPHP within 4 months after abdominal or laparoscopic hysterectomy had mean (SD) PCS of 20.0 (12.20) compared PCS of 14.9 (11.64) in patients who did not develop CPHP, ${ }^{4}$ as well as reported estimates that PCS cut-off values of 20 to 24 are clinically meaningful for poor pain outcomes and disability. ${ }^{28-30}$

Additional preoperative pain assessments included the STAI, MTS, and tonic heat stimulation. STAI is a selfreported tool for assessing anxiety via two sub-scales, each containing 20 items on a four-point rating scale; the state anxiety sub-scale measures transient anxiety at the time of scoring, while trait anxiety measures dispositional anxiety or anxiety in general. ${ }^{35}$ MTS is a dynamic assessment for central sensitization, and the presence of evoked MTS has been associated with pain augmentation. ${ }^{36,37}$ In the MTS assessment, a 180-gram von Frey filament was applied to the volar aspect of the dominant forearm, and the patient was asked to rate her perceived pain intensity from 0 to 100. Subsequently, 10 repetitive stimuli were applied to an area $1 \mathrm{~cm}$ in diameter and the pain intensity of the last stimulus was rated. MTS magnitude was calculated as the difference between the last and first pain scores, while the presence of evoked MTS was defined as MTS magnitude $>0$. Finally, preoperative pain response to tonic heat stimulation at $47^{\circ} \mathrm{C}$ predicts chronic postoperative pain, with $30 \%$ increase in risk per point of numerical rating scale (NRS). ${ }^{38}$ In this test, a Thermosensory Analyzer (TSA) II system (Medoc, Israel) was applied to the right arm. After a warning signal, the temperature rose at $5^{\circ} \mathrm{C} \cdot \mathrm{s}^{-1}$ to $47^{\circ} \mathrm{C}$ and was maintained for 7 minutes. The patient rated the pain intensity (NRS $0-10 ; 0=$ no pain, $10=$ worst pain imaginable) every 30 seconds. If the patient found the discomfort intolerable, the test would be stopped and remaining timepoints scored as 10/10 pain.

Our institutional practice for patients undergoing abdominal hysterectomy was the use of morphine patient-controlled analgesia (PCA) and paracetamol for post-operative pain relief. Patients undergoing laparoscopic hysterectomy received paracetamol, non-steroidal anti-inflammatory drugs and opioids as needed for postoperative analgesia. Intraoperative analgesic use and postoperative pain scores in the recovery area (NRS 0-10; $0=$ no pain, $10=$ worst pain imaginable) around the surgical scar at rest, when sitting at the edge of the bed, and when coughing were recorded. In addition, pain scores at postoperative 24-, 48-, and 72 hours were recorded. During the prospective trial, the attending anesthesiologists, surgeons, and outcome assessors were blinded to the preoperative assessment data and PCS scores.

Our primary outcome was the association of high PCS scores with CPHP in the 4-month pain survey. Secondary outcomes included the association of high PCS with CPHP at 6 months, the association of functional impairment with CPHP at 4- and 6-months, and the association of perioperative pain-related variables such as pre-existing pain, STAI, MTS and tonic heat stimulation tests with CPHP at 4- and 6-months. Assessment for the development of CPHP and functional impairment were performed via 4and 6-month phone surveys, based on Brandsborg et al. ${ }^{39}$ Each survey determined pain duration in terms of "I don't know/I don't remember", "less than 1 month", "1-3 months", "more than 3 months, but not now", "I still have pain, ever since the operation", and "I still have pain, it started sometime after the operation". In our study, CPHP was defined as follows: mention of any of the last three options and with pain scores of 3 or greater. Similarly, CPHP in the 6-month survey was defined as a patient who selected any of the last two above-mentioned options and with pain scores of 3 or more. The presence or absence of CPHP was treated as binary data. During the 4and 6-month surveys, we also assessed for pain-related functional impairment, defined as patient report of pain affecting her ability to either stand for $\geq 30$ minutes, sit for $\geq 30$ minutes, or walk up or down stairs. Impairment in any of these activities was considered positive for pain-related functional impairment in this study.

\section{Statistical Analysis}

Total sample size of 164 (63 in high PCS and 101 in low PCS) would achieve $80 \%$ power to detect CPHP with an odds ratio of 2.3 based on following assumptions: proportion of CPHP in low PCS of $20 \%$, group proportion 1.6, and level of significance as 5\%. Two-sided Fisher's exact test statistic was used to calculate the sample size.

The endpoint of CPHP, and primary outcome of high PCS versus low PCS were analyzed as binary variables. The presence of evoked MTS and pain-related functional impairment were analyzed as binary outcomes, while STAI, MTS magnitude, and tonic heat stimulation were treated as continuous variables. Demographic, clinical and anesthetic variables were summarized based on PCS groups - "high PCS" and "low PCS". Categorical variables were presented as frequency with corresponding 
proportion, while all continuous variables were presented as mean (standard deviation, SD) based on high and low PCS groups. The difference in categorical and continuous variables between the high and low PCS groups were tested using Fisher's exact test and two-sample Student's $t$-test, respectively. Univariate and multivariable logistic regression models were used to quantify the association between potential covariates and the primary and secondary outcomes. The association from logistic regression was expressed using odds ratio (OR) and corresponding 95\% confidence intervals (95\% CI). Stepwise variable selection method was used to finalize the multivariable logistic regression model. We also looked at the area under the curve (AUC) from receiver operating characteristics (ROC) curve based on the generated multivariate model. Significance level was set at 0.05, all tests were 2-tailed, and SAS version 9.4 software (SAS Institute, Cary, NC, USA) was used.

\section{Results}

Data from 216 patients undergoing elective abdominal or laparoscopic hysterectomy for benign indications at $\mathrm{KK}$ Women's and Children's Hospital, Singapore were analyzed. All patients completed the preoperative PCS, STAI, MTS, and tonic heat stimulation assessments and underwent hysterectomy as scheduled. Of 216 patients, 72 (33.3\%) had high PCS, while 144 (66.7\%) had low PCS.
The response rates on the phone surveys at 4- and 6months were 79.6\% (172 patients) and 69.4\% (150 patients) respectively. At 4 months, 63/172 (36.6\%) patients had high PCS, of whom 26/63 (41.3\%) developed CPHP, compared to $109 / 172$ (63.4\%) with low PCS, of whom 24/109 (22.0\%) developing CPHP. This was statistically significant with OR 2.49 [95\% CI 1.27 to 4.89], $\mathrm{p}=0.0082$. At 6 months, 53/150 (35.3\%) patients had high PCS and 14/53 (26.4\%) developed CPHP, while 97/150 (64.7\%) had low PCS with 10/97 (10.3\%) developing CPHP (OR 3.12 [95\% CI 1.28 to 7.64], $\mathrm{p}=0.0126$ ). All 172 and 150 patients at 4- and 6-month phone surveys, respectively, were included in the final analysis. The study flow diagram is illustrated in Figure 1.

Baseline patient and surgical characteristics are summarized in Table 1. Age, height, weight, ASA status, race, education level, history of previous surgery (cesarean delivery, myomectomy, cystectomy, or inguinal hernia repair), type of hysterectomy (abdominal or laparoscopic), concomitant surgery, and surgical duration were not significantly associated with both high and low PCS groups.

Baseline pain-related variables classified according to preoperative PCS are summarized in Table 2. In the high PCS group, the mean (SD) of total PCS was 30.0 (7.9), and is significantly higher compared to 9.0 (4.7) in the low PCS group $(\mathrm{p}<0.0001)$. Furthermore, mean $(\mathrm{SD})$ total STAI score in the high PCS group was significantly higher

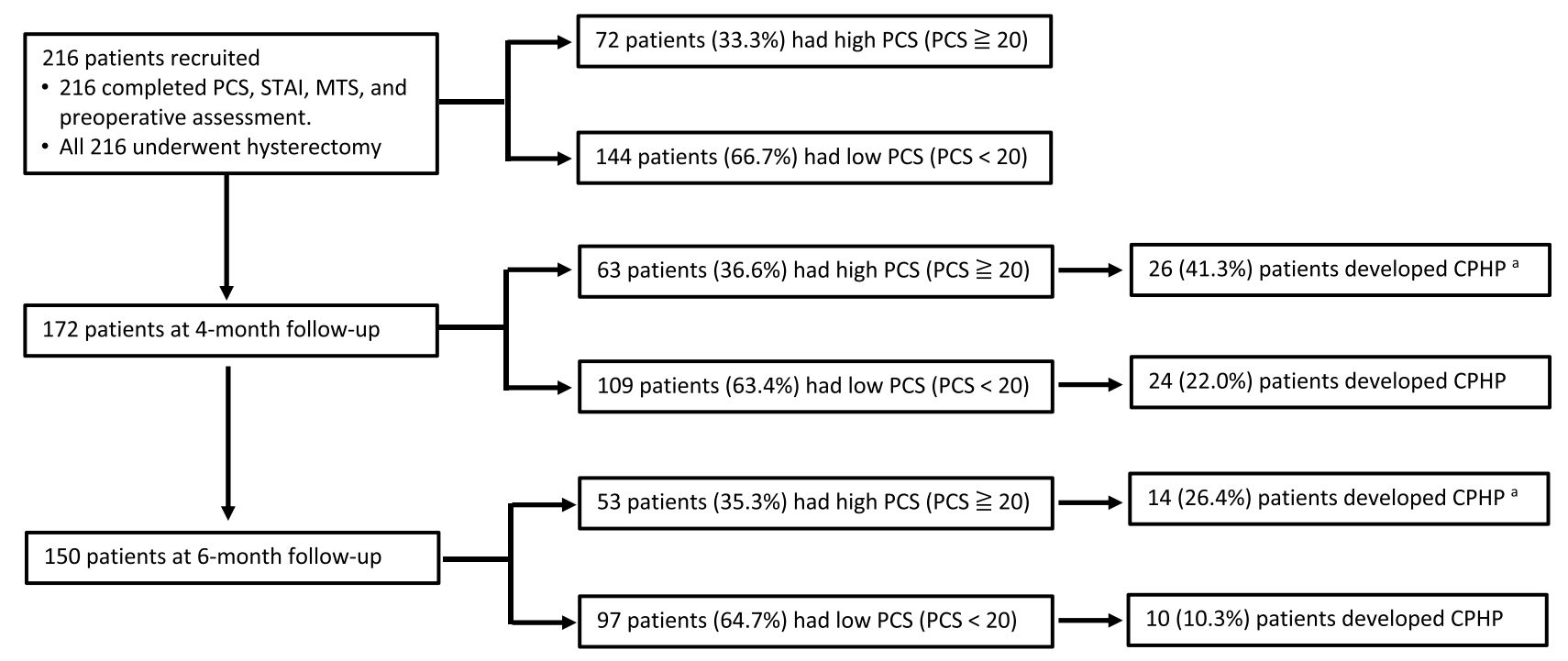

Figure I Study flow diagram. Data from 216 patients undergoing hysterectomy were included in our analysis, all of whom completed preoperative assessment, including pain catastrophizing scale (PCS), state-trait anxiety inventory (STAI), and mechanical temporal summation (MTS). The patients were classified according to high PCS (PCS $\geq 20$ ) and low PCS $(\mathrm{PCS}<20)$, with chronic post-hysterectomy pain $(\mathrm{CPHP})$ at 4 months being our primary endpoint.

Note: ${ }^{a} \mathrm{CPHP}$ incidence in the high PCS group at both 4- and 6-months were significantly different $(\mathrm{P}<0.05)$ compared to the low PCS group based on univariate and multivariable analysis.

Abbreviations: PCS, pain catastrophizing scale; STAl, state-trait anxiety inventory; MTS, mechanical temporal summation; CPHP, chronic post-hysterectomy pain. 
Table I Demographic and Surgical Characteristics of Patients Based on Status of High PCS (PCS $\geq 20)$ and Low PCS (PCS $<20)$. Values are Presented as Mean (SD) or Frequency (\%) as Appropriate

\begin{tabular}{|c|c|c|}
\hline Characteristics & High PCS (PCS $\geq 20), n=72$ & Low PCS $(P C S<20), n=144$ \\
\hline Age (years), mean (SD) & $49.0(7.1)$ & $48.6(5.3)$ \\
\hline Weight (kg), mean (SD) & $62.9(11.2)$ & $65.2(13.9)$ \\
\hline Height $(m)$, mean (SD) & $1.6(0.1)$ & $1.6(0.1)$ \\
\hline \multicolumn{3}{|l|}{ ASA physical status, $n(\%)$} \\
\hline I & $35 / 72(48.6 \%)$ & $54 / 144(37.5 \%)$ \\
\hline 2 & $37 / 72(51.4 \%)$ & $90 / 144(62.5 \%)$ \\
\hline \multicolumn{3}{|l|}{ Race, n (\%) } \\
\hline Chinese & $47 / 72(65.3 \%)$ & $101 / 144(70.1 \%)$ \\
\hline Malay & $15 / 72(20.8 \%)$ & $27 / 144(18.8 \%)$ \\
\hline Indian & $4 / 72(5.6 \%)$ & $5 / 144(3.5 \%)$ \\
\hline Others & $6 / 72(8.3 \%)$ & II/I44 (7.6\%) \\
\hline \multicolumn{3}{|l|}{ Highest educational level, $n$ (\%) } \\
\hline No education/primary school & $18 / 72(25.0 \%)$ & $27 / 144(18.8 \%)$ \\
\hline Secondary school/vocational/technical school & $43 / 72(59.7 \%)$ & $95 / 144(66.0 \%)$ \\
\hline Junior college/polytechnic/university & $1 \mathrm{I} / 72(15.3 \%)$ & $22 / 144(15.3 \%)$ \\
\hline Previous abdominal/pelvic surgery, $\mathrm{n}(\%)$ & $25 / 71$ (35.2\%) & $54 / 144(37.5 \%)$ \\
\hline \multicolumn{3}{|l|}{ Hysterectomy type, n (\%) } \\
\hline Open abdominal hysterectomy & $37 / 72(51.4 \%)$ & $80 / 144$ (55.6\%) \\
\hline Laparoscopic hysterectomy & $35 / 72(48.6 \%)$ & $64 / 144(44.4 \%)$ \\
\hline Surgical duration (hrs), mean (SD) & $2.3(I . I)$ & $2.3(0.8)$ \\
\hline
\end{tabular}

Abbreviations: PCS, pain catastrophizing scale; ASA, American Society of Anesthesiologists.

than the low PCS group (91.6 (16.9) vs 76.4 (11.3), $\mathrm{p}<0.0001)$. High PCS was associated with significantly higher MTS magnitude compared to low PCS (10.2 (13.1) vs 5.8 (10.5), $\mathrm{p}=0.0155)$, as well as higher prevalence of evoked MTS (65.3\% vs 43.1\%, $\mathrm{p}=0.0024)$. Average and worst preoperative pain scores and preoperative pain affecting daily living were similar between the groups. Patients with high PCS had significantly higher intraoperative morphine requirements $(9.1$ (2.6) $\mathrm{mg}$ vs 8.2 (2.2) $\mathrm{mg}, \mathrm{p}=0.0110$ ), but intraoperative fentanyl and opioids administered in the recovery area were similar. Finally, the high PCS group had slightly higher resting pain scores at 24 hours $(2.4(2.7)$ vs $1.5(2.0), \mathrm{p}=0.171)$. Variables assessed during the 4- and 6-month phone surveys are presented in Supplementary Table 1.

Table 3 summarizes the results of univariate and multivariable logistic regression analyses of variables associated with CPHP. Based on univariate analysis, high total PCS scores were associated with increased odds (OR 2.49 [95\% CI 1.27 to 4.89], $\mathrm{p}=0.0082$ ) of developing CPHP within 4 months. The rumination (OR 1.09 [95\% CI 1.01 to 1.17], $\mathrm{p}=0.0357$ ) and helplessness (OR 1.07 [95\% CI 1.02 to 1.13], $\mathrm{p}=0.0104)$ scores were also significantly associated with CPHP at 4 months. Similar results were seen at 6 months, with high total PCS (OR 3.12 [95\% CI 1.276 to 7.644], $\mathrm{p}=0.0126$ ), rumination (OR 1.149 [95\% CI 1.03 to 1.28], $\mathrm{p}=0.0120$ ) and helplessness (OR 1.10 [95\% CI 1.03 to 1.19], $\mathrm{p}=0.0079)$ scores associated with CPHP development. Additionally, total STAI scores (OR 1.03 [95\% CI 1.00 to 1.05], $\mathrm{p}=0.0222$ ), presence of evoked MTS (OR 2.75 [95\% CI 1.36 to 5.55], $\mathrm{p}=0.0047$ ), and increasing MTS magnitude (OR 1.07 [95\% CI 1.03 to 1.10], $\mathrm{p}=0.0001$ ) were associated with CPHP at 4 months. However, of these three additional pain-related variables, only increasing MTS magnitude was associated with CPHP at 6 months (OR 1.07 [95\% CI 1.04 to 1.11], $\mathrm{p}=0.0001$ ).

Multivariable analysis showed that the presence of history of previous abdominal or pelvic surgery; total $\mathrm{PCS} \geq 20$; and presence of evoked MTS predicted CPHP development within 4 months with AUC of 0.691 . Similarly, total PCS $\geq 20$ and increasing MTS magnitude predicted CPHP at 6 months, with AUC of 0.759 .

Univariate and multivariable associations with painrelated functional impairment are summarized in Table 4. 
Table 2 Preoperative Pain Assessment, Perioperative Analgesia Requirements and Pain Outcomes Based on Status of High PCS $(P C S \geq 20)$ and Low PCS (PCS<20). Values Presented as Mean (SD) or Frequency (\%) as Appropriate

\begin{tabular}{|c|c|c|c|}
\hline Characteristics & High PCS $(P C S \geq 20) n=72$ & Low PCS $(P C S<20) n=144$ & P-value \\
\hline \multicolumn{4}{|l|}{ Preoperative assessment } \\
\hline \multicolumn{4}{|l|}{ PCS score, mean (SD) } \\
\hline Total & $30.0(7.9)$ & $9.0(4.7)$ & $<0.0001$ \\
\hline Rumination score & II.5 (3.0) & $4.9(2.7)$ & $<0.0001$ \\
\hline Magnification score & $6.3(2.4)$ & $1.8(1.6)$ & $<0.0001$ \\
\hline Helplessness score & $12.3(4.8)$ & $2.4(2.3)$ & $<0.0001$ \\
\hline \multicolumn{4}{|l|}{ STAI score, mean (SD) } \\
\hline Total & $91.6(16.9)$ & $76.4(11.3)$ & $<0.0001$ \\
\hline State anxiety score & $50.1(10.0)$ & $43.5(8.1)$ & $<0.0001$ \\
\hline Trait anxiety score & $41.6(9.9)$ & $32.9(4.9)$ & $<0.0001$ \\
\hline MTS magnitude, mean (SD) & $10.2(13.1)$ & $5.8(10.5)$ & 0.0155 \\
\hline Presence of evoked MTS, n (\%) & $47 / 72(65.3 \%)$ & $62 / 144$ (43.1\%) & 0.0024 \\
\hline Presence of preoperative pain in lower abdomen, $\mathrm{n}(\%)$ & $6 / 72(8.3 \%)$ & $9 / 144(6.3 \%)$ & 1.0000 \\
\hline Average preoperative pain score (NRS 0 to 10 ), mean (SD) & $3.0(5.0)$ & $2.0(1.0)$ & 0.3129 \\
\hline Worst preoperative pain score (NRS 0 to 10 ), mean (SD) & $5.5(3.0)$ & $2.0(0.0)$ & 0.0680 \\
\hline Pain affecting activities of daily living, $n$ (\%) & & & 0.4545 \\
\hline Not at all & $4 / 6(66.7 \%)$ & $5 / 6(83.3 \%)$ & \\
\hline Some & $2 / 6(33.3 \%)$ & $0(0.0 \%)$ & \\
\hline A lot, very much & $0(0.0 \%)$ & $1 / 6(16.7 \%)$ & \\
\hline Presence of pain during sexual intercourse, $n(\%)$ & $7 / 72(9.7 \%)$ & $13 / 144$ (9.0\%) & 0.1011 \\
\hline \multicolumn{4}{|l|}{ Perioperative assessment } \\
\hline \multicolumn{4}{|l|}{ Perioperative analgesia } \\
\hline Intraoperative morphine $(\mathrm{mg})$, mean $(\mathrm{SD})$ & $9.1(2.6)$ & $8.2(2.2)$ & 0.0110 \\
\hline Intraoperative fentanyl (mcg), mean (SD) & $82.8(41.2)$ & $79.3(43.5)$ & 0.5710 \\
\hline PACU morphine (mg), mean (SD) & $0.4(1.2)$ & $0.4(1.2)$ & 0.8123 \\
\hline PACU fentanyl (mcg), mean (SD) & $4.6(17.3)$ & $3.6(15.9)$ & 0.7000 \\
\hline Pain score on discharge from PACU, mean (SD) & $1.9(1.5)$ & $1.6(1.4)$ & 0.1494 \\
\hline \multicolumn{4}{|l|}{ Postoperative assessment } \\
\hline 24-hour pain score at rest, mean (SD) & $2.4(2.7)$ & $1.5(2.0)$ & 0.0171 \\
\hline 0 to 24-hour morphine consumption (mg), mean (SD) & $5.7(8.3)$ & $5.1(7.3)$ & 0.6003 \\
\hline 48-hour pain score at rest, mean (SD) & $1.3(2.1)$ & $0.9(1.4)$ & 0.0813 \\
\hline 24 to 48 -hour morphine consumption (mg), mean (SD) & $1.7(4.1)$ & $1.2(2.8)$ & 0.3894 \\
\hline 72-hour pain score at rest, mean (SD) & $0.8(1.6)$ & $0.4(1.0)$ & 0.1035 \\
\hline 48 to 72 -hour morphine consumption (mg), mean (SD) & $0.2(1.5)$ & $0.0(0.2)$ & 0.4090 \\
\hline Length of surgical incision at skin $(\mathrm{cm})$, mean (SD) & $15.7(2.4)$ & $15.7(2.4)$ & 0.9938 \\
\hline
\end{tabular}

Abbreviations: PCS, pain catastrophizing scale; STAI, state-trait anxiety inventory; NRS, numerical pain score; PACU, post-anesthesia care unit; MTS, mechanical temporal summation.

In the high PCS group, 31/62 (50.0\%) patients reported pain affecting their ability to stand for $\geq 30$ minutes, sit for $\geq 30$ minutes, or walk up or down stairs at 4 months, compared to $47 / 106$ (44.3\%) in the low PCS group. Based on univariate analysis, total $\mathrm{PCS} \geq 20$ was not associated with functional impairment at 4 months, although higher MTS magnitude (OR 1.05 [95\% CI 1.01 to 1.08], $\mathrm{p}=0.0055)$ and the presence of CPHP (OR $6.82[95 \%$ CI 3.16 to 14.76$], \mathrm{p}=0.0001$ ) were associated with functional impairment. Utilizing multivariable analysis, the presence of five factors: (1) Malay or Indian race; (2) increasing number of children delivered via cesarean delivery; (3) increasing total STAI score; (4) increasing MTS magnitude; and (5) lower pain score at 6.5 minutes during tonic heat stimulation predicted functional impairment at 4 months with AUC of 0.739 .

\section{Discussion}

In this study, we found that preoperative PCS $\geq 20$, as well as helplessness and rumination sub-scores were independently associated with CPHP at both 4- and 6-months. Other factors associated with CPHP at 4 months include 
Table 3 Univariate and Multivariable Analyses of Variables Associated with Development of Chronic Post-Hysterectomy Pain (CPHP) at 4- and 6 Months. Values Presented as Odds Ratio [95\% Cl]

\begin{tabular}{|c|c|c|c|c|c|c|c|c|}
\hline \multirow[t]{2}{*}{ Variables } & \multicolumn{4}{|c|}{ Presence of CPHP at 4 Months } & \multicolumn{4}{|c|}{ Presence of CPHP at 6 Months } \\
\hline & $\begin{array}{l}\text { Univariate } \\
\text { Analysis Odds } \\
\text { Ratio }[95 \% \mathrm{Cl}]\end{array}$ & p-value & $\begin{array}{l}\text { Multivariable } \\
\text { Analysis Odds } \\
\text { Ratio }[95 \% \mathrm{Cl}]\end{array}$ & $\begin{array}{l}\mathrm{p} \text { - } \\
\text { value }\end{array}$ & $\begin{array}{l}\text { Univariate } \\
\text { Analysis Odds } \\
\text { Ratio }[95 \% \mathrm{Cl}]\end{array}$ & p-value & $\begin{array}{l}\text { Multivariable } \\
\text { Analysis Odds } \\
\text { Ratio }[95 \% \mathrm{Cl}]\end{array}$ & $\begin{array}{l}\mathrm{p}- \\
\text { value }\end{array}$ \\
\hline $\begin{array}{l}\text { Age } \\
\text { BMI } \\
\text { Race }\end{array}$ & $\begin{array}{l}0.99[0.94 \text { to } 1.05] \\
0.98[0.92 \text { to } 1.04]\end{array}$ & $\begin{array}{l}0.7881 \\
0.4712 \\
0.5330^{a}\end{array}$ & & & $\begin{array}{l}1.00[0.93 \text { to } 1.07] \\
1.04[0.96 \text { to } 1.13]\end{array}$ & $\begin{array}{l}0.9653 \\
0.3023 \\
0.9357^{\mathrm{a}}\end{array}$ & & \\
\hline Chinese & \multicolumn{2}{|l|}{ Reference } & & & \multicolumn{2}{|l|}{ Reference } & & \\
\hline $\begin{array}{l}\text { Malay } \\
\text { Indian } \\
\text { Others }\end{array}$ & $\begin{array}{l}1.82[0.77 \text { to } 4.32] \\
0.88[0.17 \text { to } 4.59] \\
0.79[0.21 \text { to } 3.06]\end{array}$ & $\begin{array}{l}0.1738 \\
0.8817 \\
0.7378\end{array}$ & & & $\begin{array}{l}\mathrm{I} .34[0.40 \text { to } 4.48] \\
\mathrm{I} .43[0.15 \text { to } 13.55] \\
\mathrm{I} .43[0.28 \text { to } 7.30]\end{array}$ & $\begin{array}{l}0.6317 \\
0.7570 \\
0.6697\end{array}$ & & \\
\hline $\begin{array}{l}\text { Highest educational level } \\
\text { No education/primary }\end{array}$ & $1.21[0.55$ to 2.66$]$ & $\begin{array}{l}0.6220^{a} \\
0.6352\end{array}$ & & & $0.97[0.35$ to $2.7 \mathrm{I}]$ & $\begin{array}{l}0.3466^{a} \\
0.9545\end{array}$ & & \\
\hline Secondary school/ & \multicolumn{2}{|l|}{ Reference } & & & \multicolumn{2}{|l|}{ Reference } & & \\
\hline $\begin{array}{l}\text { Junior college/polytechnic/ } \\
\text { university }\end{array}$ & $0.69[0.26$ to 1.88$]$ & 0.4691 & & & $0.22[0.03$ to 1.72$]$ & 0.1471 & & \\
\hline $\begin{array}{l}\text { Previous surgery at } \\
\text { abdominal or pelvic region }\end{array}$ & $1.94[0.99$ to 3.81$]$ & 0.0535 & $2.03[1.00$ to 4.11$]$ & 0.0495 & $1.36[0.56$ to 3.27$]$ & 0.4962 & & \\
\hline $\begin{array}{l}\text { Surgical type } \\
\text { Open abdominal } \\
\text { hysterectomy } \\
\text { Laparoscopic hysterectomy }\end{array}$ & $\begin{array}{l}1.08[0.56 \text { to } 2.09] \\
0.92[0.48 \text { to } 1.78]\end{array}$ & $\begin{array}{l}0.8117 \\
0.8117\end{array}$ & & & $\begin{array}{l}0.79[0.33 \text { to } 1.90] \\
1.27[0.53 \text { to } 3.08]\end{array}$ & $\begin{array}{l}0.5927 \\
0.5927\end{array}$ & & \\
\hline $\begin{array}{l}\text { PCS categories } \\
\text { High total PCS }\end{array}$ & $2.49[1.27$ to 4.89$]$ & 0.0082 & $2.16[1.06$ to 4.41$]$ & 0.0339 & $3.12[1.28$ to 7.64$]$ & 0.0126 & $2.66[1.01$ to 6.97$]$ & 0.0472 \\
\hline Low total PCS & \multicolumn{2}{|l|}{ Reference } & \multicolumn{2}{|l|}{ Reference } & \multicolumn{2}{|l|}{ Reference } & \multicolumn{2}{|l|}{ Reference } \\
\hline $\begin{array}{l}\text { PCS domains } \\
\text { Rumination score } \\
\text { Magnification score } \\
\text { Helplessness score }\end{array}$ & 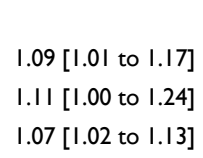 & $\begin{array}{l}0.0357 \\
0.0585 \\
0.0104\end{array}$ & & & $\begin{array}{l}1.15[1.03 \text { to } 1.28] \\
1.10[0.95 \text { to } 1.27] \\
1.10[1.03 \text { to } 1.19]\end{array}$ & $\begin{array}{l}0.0120 \\
0.2101 \\
0.0079\end{array}$ & & \\
\hline $\begin{array}{l}\text { STAl score } \\
\text { Total } \\
\text { State anxiety score } \\
\text { Trait anxiety score }\end{array}$ & $\begin{array}{l}1.03[1.00 \text { to } 1.05] \\
1.03[0.99 \text { to } 1.07] \\
1.06[1.01 \text { to } 1.11]\end{array}$ & $\begin{array}{l}0.0222 \\
0.1380 \\
0.0107\end{array}$ & & & $\begin{array}{l}1.01[0.98 \text { to } 1.04] \\
1.00[0.96 \text { to } 1.05] \\
1.05[0.99 \text { to } 1.11]\end{array}$ & $\begin{array}{l}0.3831 \\
0.9115 \\
0.1261\end{array}$ & & \\
\hline $\begin{array}{l}\text { MTS magnitude } \\
\text { Presence of evoked MTS } \\
\text { Presence of preoperative pain } \\
\text { in lower abdomen } \\
\text { Presence of pain during } \\
\text { sexual intercourse }\end{array}$ & $\begin{array}{l}1.07[1.03 \text { to } 1.10] \\
2.75[1.36 \text { to } 5.55] \\
2.60[0.72 \text { to } 9.41] \\
2.04[0.72 \text { to } 5.83]\end{array}$ & $\begin{array}{l}0.0001 \\
0.0047 \\
0.1456 \\
0.1812\end{array}$ & $2.44[1.18$ to 5.08$]$ & 0.0168 & $\begin{array}{l}1.07[1.04 \text { to } 1.1 \mathrm{I}] \\
2.5 \mathrm{I}[0.97 \text { to } 6.46] \\
1.82[0.34 \text { to } 9.60] \\
2.60[0.73 \text { to } 9.26]\end{array}$ & $\begin{array}{l}0.0001 \\
0.0571 \\
0.4812 \\
0.1402\end{array}$ & $1.07[1.03$ to 1.11$]$ & 0.0002 \\
\hline Area under ROC (AUC) & & & 0.6910 & & & & 0.7590 & \\
\hline
\end{tabular}

Note: ${ }^{a}$ Denotes type 3 p-values.

Abbreviations: CPHP, chronic post-hysterectomy pain; BMI, body mass index; STAI, state-trait anxiety inventory; PCS, pain catastrophizing scale; ROC, receiver-operator curve; AUC, area under the curve; MTS, mechanical temporal summation. 
Table 4 Univariate and Multivariable Analyses of Variables Associated with Functional Impairment, Defined as Pain Affecting Ability to Stand for $\geq 30$ Minutes, Sit for $\geq 30$ Minutes, or Walk Up or Down Stairs at 4- and 6 Months. Values Presented as Odds Ratio [95\% Cl]

\begin{tabular}{|c|c|c|c|c|c|c|c|c|}
\hline \multirow[t]{2}{*}{ Variables } & \multicolumn{4}{|c|}{ Adverse Effect on Functional Outcomes at 4 Months } & \multicolumn{4}{|c|}{ Adverse Effect on Functional Outcomes at 6 Months } \\
\hline & $\begin{array}{l}\text { Univariate } \\
\text { Analysis Odds } \\
\text { Ratio }[95 \% \mathrm{Cl}]\end{array}$ & p-value & $\begin{array}{l}\text { Multivariable } \\
\text { Analysis Odds } \\
\text { Ratio }[95 \% \mathrm{Cl}]\end{array}$ & p-value & $\begin{array}{l}\text { Univariate Anal } \\
\text { sis Odds Ratio } \\
{[95 \% \mathrm{Cl}]}\end{array}$ & p-value & $\begin{array}{l}\text { Multivariable } \\
\text { Analysis Odds } \\
\text { Ratio }[95 \% \mathrm{Cl}]\end{array}$ & $\begin{array}{l}\mathrm{p}- \\
\text { value }\end{array}$ \\
\hline Age & $0.97\left[\begin{array}{ll}0.92 \text { to } 1.02] \\
0\end{array}\right.$ & 0.2754 & & & $0.99[0.93$ to 1.04$]$ & 0.6421 & & \\
\hline BMI & $1.03[0.97$ to 1.09$]$ & 0.3204 & & & $1.00[0.94$ to 1.07$]$ & 0.9245 & & \\
\hline \multirow[t]{2}{*}{ Race } & & $0.0765^{a}$ & & $0.0493^{\text {a }}$ & & $0.5387^{\mathrm{a}}$ & & \\
\hline & \multicolumn{2}{|l|}{ Reference } & \multicolumn{2}{|l|}{ Reference } & \multicolumn{2}{|l|}{ Reference } & & \\
\hline Malay & 2.33 [0.99 to 5.52$]$ & 0.0536 & $2.09[0.83$ to 5.22$]$ & 0.1160 & $0.78[0.28$ to 2.17$]$ & 0.6327 & & \\
\hline Indian & $\begin{array}{l}4.12[0.80 \text { to } \\
21.24]\end{array}$ & 0.0909 & 5.11 [0.97 to 26.97$]$ & 0.0549 & $\begin{array}{l}2.92[0.47 \text { to } \\
18.24]\end{array}$ & 0.2513 & & \\
\hline Others & $0.69[0.20$ to 2.40$]$ & 0.5560 & $0.43[0.11$ to 1.69$]$ & 0.2255 & $0.56[0.11$ to 2.81$]$ & 0.4780 & & \\
\hline \multirow{4}{*}{$\begin{array}{l}\text { Highest educational level } \\
\text { No education/primary school } \\
\text { Secondary school/vocational/ } \\
\text { technical school } \\
\text { Junior college/polytechnic/ } \\
\text { university }\end{array}$} & & $0.4745^{\text {a }}$ & & & & $0.2313^{\mathrm{a}}$ & \multirow{4}{*}{$0.29[0.10$ to 0.87$]$} & \multirow{3}{*}{0.0277} \\
\hline & $0.62[0.29$ to 1.34$]$ & 0.2223 & & & $0.48[0.19$ to 1.23$]$ & 0.1262 & & \\
\hline & \multicolumn{2}{|l|}{ Reference } & & & \multicolumn{2}{|l|}{ Reference } & & \\
\hline & $0.87[0.37$ to 2.07$]$ & 0.7584 & & & $1.24[0.48$ to 3.20$]$ & 0.6601 & & 0.5042 \\
\hline $\begin{array}{l}\text { Lives in private residence } \\
\text { (reference government- } \\
\text { subsidized housing) }\end{array}$ & $\begin{array}{l}2.38[0.42 \text { to } \\
13.35]\end{array}$ & 0.3250 & & & $\begin{array}{l}4.27[0.75 \text { to } \\
24.16]\end{array}$ & 0.1010 & 8.87 [1.19 to 66.26$]$ & 0.0333 \\
\hline $\begin{array}{l}\text { Number of children via vaginal } \\
\text { delivery }\end{array}$ & $0.95[0.75$ to 1.21$]$ & 0.6814 & & & $0.91[0.69$ to 1.21$]$ & 0.5078 & & \\
\hline $\begin{array}{l}\text { Number of children via } \\
\text { caesarean section }\end{array}$ & $1.38[0.92$ to 2.09$]$ & 0.1213 & $1.63[1.01$ to 2.64$]$ & 0.0454 & $1.25[0.82$ to 1.92$]$ & 0.2985 & & \\
\hline $\begin{array}{l}\text { Previous surgery at abdominal } \\
\text { or pelvic region }\end{array}$ & $1.79[0.49$ to 6.60$]$ & 0.3805 & & & $1.21[0.28$ to 5.30$]$ & 0.7974 & & \\
\hline \multicolumn{9}{|l|}{ Surgical type } \\
\hline $\begin{array}{l}\text { Open abdominal } \\
\text { hysterectomy }\end{array}$ & & & & & & & & \\
\hline Laparoscopic hysterectomy & $1.32[0.72$ to 2.43$]$ & 0.3652 & & & I.7I [0.85 to 3.44$]$ & 0.1306 & & \\
\hline \multicolumn{9}{|l|}{ PCS categories } \\
\hline \multirow{2}{*}{$\begin{array}{l}\text { High total PCS } \\
\text { Low total PCS }\end{array}$} & $1.26[0.67$ to 2.35$]$ & 0.4781 & & & $1.62[0.80$ to 3.29$]$ & 0.1812 & & \\
\hline & \multicolumn{2}{|l|}{ Reference } & & & \multicolumn{2}{|l|}{ Reference } & & \\
\hline PCS domains & & & & & & & & \\
\hline Rumination score & $1.05[0.98$ to 1.13$]$ & 0.1830 & & & $1.08[1.00$ to 1.18$]$ & 0.0598 & & \\
\hline Magnification score & $1.07[0.97$ to 1.19$]$ & 0.1938 & & & $1.04[0.92$ to 1.17$]$ & 0.5490 & & \\
\hline Helplessness score & $1.04[0.99$ to 1.09$]$ & 0.1591 & & & $1.07\left[\begin{array}{ll}1.00 \text { to } 1.13] \\
0\end{array}\right.$ & 0.0360 & $\begin{array}{l}1.062[0.992 \text { to } \\
1.136]\end{array}$ & 0.0827 \\
\hline \multicolumn{9}{|l|}{ STAI score } \\
\hline Total & $1.00[0.98$ to 1.03$]$ & 0.6476 & $\begin{array}{l}1.058[1.007 \text { to } \\
1.111]\end{array}$ & 0.0253 & $1.01[0.98$ to 1.03$]$ & 0.5074 & & \\
\hline State anxiety score & $0.99[0.95$ to 1.02$]$ & 0.3693 & & & $0.99[0.96$ to 1.03$]$ & 0.7045 & & \\
\hline Trait anxiety score & $1.05[1.00$ to 1.09$]$ & 0.0543 & & & $1.04[0.99$ to 1.10$]$ & 0.0875 & & \\
\hline MTS magnitude & $1.05[1.01$ to 1.08$]$ & 0.0055 & $\begin{array}{l}1.044[1.012 \text { to } \\
1.078]\end{array}$ & 0.0073 & $1.03[1.00$ to 1.06$]$ & 0.0545 & $\begin{array}{l}1.005[0.972 \text { to } \\
1.040]\end{array}$ & 0.7684 \\
\hline Presence of evoked MTS & $1.49[0.81$ to 2.75$]$ & 0.2002 & & & 1.18 [0.59 to 2.35$]$ & 0.6406 & & \\
\hline $\begin{array}{l}\text { Tonic heat stimulation at } 6.5 \\
\text { minutes }\end{array}$ & $0.81[0.58$ to 1.12$]$ & 0.2059 & $\begin{array}{l}0.712[0.498 \text { to } \\
1.019]\end{array}$ & 0.0635 & $0.83[0.58$ to 1.19$]$ & 0.3138 & & \\
\hline
\end{tabular}

(Continued) 
Table 4 (Continued).

\begin{tabular}{|c|c|c|c|c|c|c|c|c|}
\hline \multirow[t]{2}{*}{ Variables } & \multicolumn{4}{|c|}{ Adverse Effect on Functional Outcomes at 4 Months } & \multicolumn{4}{|c|}{ Adverse Effect on Functional Outcomes at 6 Months } \\
\hline & $\begin{array}{l}\text { Univariate } \\
\text { Analysis Odds } \\
\text { Ratio }[95 \% \mathrm{Cl}]\end{array}$ & p-value & $\begin{array}{l}\text { Multivariable } \\
\text { Analysis Odds } \\
\text { Ratio }[95 \% \mathrm{Cl}]\end{array}$ & p-value & $\begin{array}{l}\text { Univariate Anal } \\
\text { sis Odds Ratio } \\
{[95 \% \mathrm{Cl}]}\end{array}$ & p-value & $\begin{array}{l}\text { Multivariable } \\
\text { Analysis Odds } \\
\text { Ratio }[95 \% \mathrm{Cl}]\end{array}$ & $\begin{array}{l}\mathrm{p} \text { - } \\
\text { value }\end{array}$ \\
\hline $\begin{array}{l}\text { Presence of preoperative pain in } \\
\text { lower abdomen }\end{array}$ & $1.79[0.49$ to 6.60$]$ & 0.3805 & & & $1.21[0.28$ to 5.30$]$ & 0.7974 & & \\
\hline $\begin{array}{l}\text { Presence of pain during sexual } \\
\text { intercourse }\end{array}$ & $1.55[0.55$ to 4.37$]$ & 0.4099 & & & $0.88[0.26$ to 3.01$]$ & 0.8373 & & \\
\hline Presence of CPHP at 4 months & $\begin{array}{l}6.82[3.16 \text { to } \\
14.76]\end{array}$ & 0.0001 & & & $\begin{array}{l}5.31[2.42 \text { to } \\
11.65]\end{array}$ & 0.0001 & $\begin{array}{l}6.132[2.614 \text { to } \\
14.387]\end{array}$ & 0.0001 \\
\hline Area under ROC (AUC) & & & 0.7390 & & & & 0.7630 & \\
\hline
\end{tabular}

Note: ${ }^{a}$ Denotes type 3 p-values.

Abbreviations: CPHP, chronic post-hysterectomy pain; BMI, body mass index; STAl, state-trait anxiety inventory; PCS, pain catastrophizing scale; ROC, receiver-operator curve; AUC, area under the curve; MTS, mechanical temporal summation.

increased anxiety (assessed by STAI), increased MTS magnitude, and the presence of evoked MTS, but only increased MTS magnitude was associated with CPHP at 6 months. Preoperative PCS $\geq 20$ was not associated with functional impairment, defined as pain-related impairment with standing for $\geq 30$ minutes, sitting for $\geq 30$ minutes, or walking up or down stairs. However, increasing MTS magnitude and the presence of CPHP were associated with functional impairment at 4 months, but only the presence of CPHP was found to be an independent predictor of functional impairment at 6 months.

Assessment of pain catastrophizing using the PCS avoided potential overlap of the CSQ-R with measures of depression, ${ }^{9}$ and enabled analysis of the specific catastrophizing domains associated with CPHP development. Moreover, we defined a threshold of $\mathrm{PCS} \geq 20$ a priori and determined if patients with preoperative PCS scores above this threshold were at increased risk of developing CPHP at 4- and 6-months. Our finding that preoperative $\mathrm{PCS} \geq 20$ was independently associated with CPHP at both 4- and 6-months supports the important contribution of pain catastrophizing towards CPHP development, and highlights the potential use of PCS $\geq 20$ as a risk-prediction tool for CPHP. This is demonstrated by the ability of two preoperative variables: $P C S \geq 20$ and increasing MTS magnitude, to predict the presence of CPHP at 6 months with an AUC of 0.76 .

The PCS threshold of $\geq 20$ used in this study was selected based on our prior finding that patients with CPHP at 4 months had a mean PCS of 20.0, compared to a PCS of 14.9 in those who did not develop CPHP, suggesting that a suitable PCS threshold to predict CPHP was likely between 15 and 20. Indeed, this was congruent with other studies that recommended 20 to 24 as a clinically-significant threshold for poor pain outcomes and disability, ${ }^{28-30}$ but is lower than the $\mathrm{PCS} \geq 30$ recommended by Sullivan. ${ }^{40}$ The difference in PCS thresholds chosen for this study compared to that recommended by Sullivan may be attributed to the different mode of injury studied (hysterectomy in this study, versus work-related injury by Sullivan).

Apart from pain catastrophizing, other studies have reported the association of increasing MTS magnitude, anxiety, and poorly-controlled pre- or post-operative pain with the development of chronic post-surgical pain. For instance, increasing MTS magnitude was associated with acute pain after thoracotomy ${ }^{37}$ and chronic pain after knee replacement, ${ }^{41}$ although its association with CPHP has not been well established. MTS is a validated, non-invasive dynamic assessment for central sensitization; a crucial etiological process for chronic pain. Our finding that both increasing MTS magnitude and presence of evoked MTS were associated with CPHP at 4 months suggests that MTS may be a useful predictive tool for CPHP. Similarly, preoperative anxiety has been associated with chronic post-surgical pain, ${ }^{42,43}$ and is supported by our finding that higher STAI scores are associated with CPHP at 4 months. However, while other studies associated pre-existing pain and severe postoperative pain with chronic post-surgical pain ${ }^{6}$ and CPHP, ${ }^{4,19,44-47}$ no significant association between pre- and post-operative pain scores or analgesia requirements with CPHP was found with univariate analysis, suggesting that these variables are either not associated with CPHP or our study was not powered to detect this association. 
In addition, $\mathrm{PCS} \geq 20$ was not associated with pain-related functional impairment such as standing for $\geq 30$ minutes, sitting for $\geq 30$ minutes, or walking up or down stairs, and it is possible that our study was not powered to detect this association. Nonetheless, as our patients were instructed to report pain-related impairment of these activities, it is unsurprising that the presence of CPHP was significantly associated with functional impairment at both 4- and 6 months.

Finally, patients with high PCS were associated with significantly higher STAI scores, MTS magnitude, and prevalence of evoked MTS compared to patients with low PCS. Both anxiety (assessed by STAI) and central sensitization (assessed by MTS) are individually associated with the development of chronic post-surgical pain, and this may explain their co-association with pain catastrophizing in this study. Although increased 24-hour postoperative pain scores and morphine utilization in the recovery area were noted in the high PCS group, the absolute differences may not be clinically significant.

Our study has several limitations. While we attempted to assess a wide range of clinically-relevant confounding factors encompassing demographic, psychological, social, and surgical domains in our analyses, there could be unknown association factors not included in our study. Our study results may not be generalizable to all patients undergoing hysterectomy, as we excluded patients with endometriosis and non-benign indications for hysterectomy, which may also be associated with persistent pelvic pain and functional impairment. ${ }^{48}$ Patient attrition is typically a concern given the 6-month follow up period, though our retention rates were high $(79.6 \%$ at 4 months; $69.4 \%$ at 6 months). Furthermore, our study outcomes were assessed via phone survey, and are thus susceptible to interviewer and response biases, though the assessor was blinded to the perioperative assessment and PCS scores. Finally, our study population is predominantly multi-ethnic Asian, which may limit the external validity of our results to other populations, given the potential influence of ethnic and cultural differences on psychological factors and pain.

\section{Conclusion}

In summary, we showed that preoperative $\mathrm{PCS} \geq 20$, presence of evoked MTS, and history of abdominal or pelvic surgery are associated with the development of CPHP at 4 months. Our findings highlight the association of preoperative pain catastrophizing with CPHP, and the potential use of assessment tools such as PCS in predicting CPHP development. Future studies should focus on identifying other associated factors with the aim of formulating a risk-prediction model for CPHP. Furthermore, the effectiveness of early intervention for pain catastrophizers in improving pain-related outcomes should be investigated.

\section{Data Sharing Statement}

Anonymized raw data pertaining to this secondary analysis are available upon reasonable request from the corresponding author. Data will not be made publicly available for data protection reasons.

\section{Acknowledgments}

We wish to acknowledge Ms Agnes Teo, Ms Liu Juan, and Department of Women's Anesthesia for their assistance with administrative management of the dataset.

\section{Disclosure}

This work is supported by the National Medical Research Council Transition Award (clinicaltrials.gov reference NCT02025153). The sponsor had no involvement in the design, conduct, or manuscript preparation. The authors declare that they have no competing interests in this work.

\section{References}

1. Treede RD, Rief W, Barke A, et al. A classification of chronic pain for ICD-11. Pain. 2015;156(6):1003-1007. doi:10.1097/j.pain.0000 000000000160

2. Kehlet H, Jensen TS, Woolf CJ. Persistent postsurgical pain: risk factors and prevention. Lancet. 2006;367(9522):1618-1625. doi:10.1016/S0140-6736(06)68700-X

3. Brandsborg B, Nikolajsen L, Hansen CT, Kehlet H, Jensen TS. Risk factors for chronic pain after hysterectomy: a nationwide questionnaire and database study. Anesthesiology. 2007;106(5):1003-1012. doi:10.1097/01.anes.0000265161.39932.e8

4. Sng BL, Ching YY, Han NR, et al. Incidence and association factors for the development of chronic post-hysterectomy pain at 4- and 6month follow-up: a prospective cohort study. $J$ Pain Res. 2018;11:629-636. doi:10.2147/JPR.S149102

5. Wu JM, Wechter ME, Geller EJ, Nguyen TV, Visco AG. Hysterectomy rates in the United States, 2003. Obstet Gynecol. 2007;110(5):10911095. doi:10.1097/01.AOG.0000285997.38553.4b

6. Chapman CR, Vierck CJ. The transition of acute postoperative pain to chronic pain: an integrative overview of research on mechanisms. J Pain. 2017;18(4):359.e351-359.e338. doi:10.1016/j.jpain.2016.11.004

7. Pinto PR, McIntyre T, Araujo-Soares V, Almeida A, Costa P. Psychological factors predict an unfavorable pain trajectory after hysterectomy: a prospective cohort study on chronic postsurgical pain. Pain. 2018;159(5):956-967. doi:10.1097/j.pain.0000000000001170

8. Theunissen M, Peters ML, Bruce J, Gramke HF, Marcus MA. Preoperative anxiety and catastrophizing: a systematic review and meta-analysis of the association with chronic postsurgical pain. Clin J Pain. 2012;28(9):819-841. doi:10.1097/AJP.0b013e31824549d6

9. Osman A, Barrios FX, Gutierrez PM, Kopper BA, Merrifield T, Grittmann L. The Pain Catastrophizing Scale: further psychometric evaluation with adult samples. J Behav Med. 2000;23(4):351-365. doi:10.1023/A:1005548801037 
10. Sullivan MJL, Bishop SC, Pivik J. The Pain Catastrophizing Scale: development and validation. Psychol Assess. 1995;7:524-532. doi:10.1037/1040-3590.7.4.524

11. Van Damme S, Crombez G, Eccleston C. Retarded disengagement from pain cues: the effects of pain catastrophizing and pain expectancy. Pain. 2002;100(1-2):111-118. doi:10.1016/S0304-3959(02) 00290-7

12. Keefe FJ, Lefebvre JC, Egert JR, Affleck G, Sullivan MJ, Caldwell DS. The relationship of gender to pain, pain behavior, and disability in osteoarthritis patients: the role of catastrophizing. Pain. 2000;87 (3):325-334. doi:10.1016/S0304-3959(00)00296-7

13. Martin MY, Bradley LA, Alexander RW, et al. Coping strategies predict disability in patients with primary fibromyalgia. Pain 1996;68(1):45-53. doi:10.1016/S0304-3959(96)03179-X

14. Martin CE, Johnson E, Wechter ME, Leserman J, Zolnoun DA. Catastrophizing: a predictor of persistent pain among women with endometriosis at 1 year. Hum Reprod. 2011;26(11):3078-3084. doi:10.1093/humrep/der292

15. Sullivan MJ, Lynch ME, Clark AJ. Dimensions of catastrophic thinking associated with pain experience and disability in patients with neuropathic pain conditions. Pain. 2005;113(3):310-315. doi:10.1016/j.pain.2004.11.003

16. Jacobsen PB, Butler RW. Relation of cognitive coping and catastrophizing to acute pain and analgesic use following breast cancer surgery. $J$ Behav Med. 1996;19(1):17-29. doi:10.1007/ BF01858172

17. Papaioannou M, Skapinakis P, Damigos D, Mavreas V, Broumas G, Palgimesi A. The role of catastrophizing in the prediction of postoperative pain. Pain Med. 2009;10(8):1452-1459. doi:10.1111/ j.1526-4637.2009.00730.x

18. Pavlin DJ, Sullivan MJ, Freund PR, Roesen K. Catastrophizing: a risk factor for postsurgical pain. Clin J Pain. 2005;21(1):83-90. doi:10.1097/00002508-200501000-00010

19. Pinto PR, McIntyre T, Nogueira-Silva C, Almeida A, Araujo-Soares $\mathrm{V}$. Risk factors for persistent postsurgical pain in women undergoing hysterectomy due to benign causes: a prospective predictive study. $J$ Pain. 2012;13(11):1045-1057. doi:10.1016/j.jpain.2012.07.014

20. Abbott AD, Tyni-Lenne R, Hedlund R. Leg pain and psychological variables predict outcome 2-3 years after lumbar fusion surgery. Eur Spine J. 2011;20(10):1626-1634. doi:10.1007/s00586-011-1709-6

21. Holroyd KA, Drew JB, Cottrell CK, Romanek KM, Heh V. Impaired functioning and quality of life in severe migraine: the role of catastrophizing and associated symptoms. Cephalalgia. 2007;27 (10):1156-1165. doi:10.1111/j.1468-2982.2007.01420.x

22. Jensen MK, Thomsen AB, Hojsted J. 10-year follow-up of chronic non-malignant pain patients: opioid use, health related quality of life and health care utilization. Eur J Pain. 2006;10(5):423-433. doi:10.1016/j.ejpain.2005.06.001

23. Martel MO, Wasan AD, Jamison RN, Edwards RR. Catastrophic thinking and increased risk for prescription opioid misuse in patients with chronic pain. Drug Alcohol Depend. 2013;132(1v2):335-341. doi:10.1016/j.drugalcdep.2013.02.034

24. Picavet HS, Vlaeyen JW, Schouten JS. Pain catastrophizing and kinesiophobia: predictors of chronic low back pain. Am J Epidemiol. 2002;156(11):1028-1034. doi:10.1093/aje/kwf136

25. Severeijns R, Vlaeyen JW, van den Hout MA, Weber WE. Pain catastrophizing predicts pain intensity, disability, and psychological distress independent of the level of physical impairment. Clin J Pain. 2001;17(2):165-172. doi:10.1097/00002508-200106000-00009

26. Smeets RJ, van Geel AC, Kester AD, Knottnerus JA. Physical capacity tasks in chronic low back pain: what is the contributing role of cardiovascular capacity, pain and psychological factors? Disabil Rehabil. 2007;29(7):577-586. doi:10.1080/09638280600925829

27. Sommer M, de Rijke JM, van Kleef M, et al. Predictors of acute postoperative pain after elective surgery. Clin J Pain. 2010;26(2):8794. doi:10.1097/AJP.0b013e3181b43d68
28. Scott W, Wideman TH, Sullivan MJ. Clinically meaningful scores on pain catastrophizing before and after multidisciplinary rehabilitation: a prospective study of individuals with subacute pain after whiplash injury. Clin J Pain. 2014;30(3):183-190. doi:10.1097/AJP.0b013e31828eee6c

29. Sullivan MJ, Adams H, Rhodenizer T, Stanish WD. A psychosocial risk factor-targeted intervention for the prevention of chronic pain and disability following whiplash injury. Phys Ther. 2006;86(1):8-18. doi:10.1093/ptj/86.1.8

30. Wideman TH, Adams H, Sullivan MJ. A prospective sequential analysis of the fear-avoidance model of pain. Pain. 2009;145(12):45-51. doi:10.1016/j.pain.2009.04.022

31. Riley JL, Robinson ME. CSQ: five factors or fiction? Clin J Pain. 1997;13(2):156-162. doi:10.1097/00002508-199706000-00010

32. Adams H, Ellis T, Stanish WD, Sullivan MJ. Psychosocial factors related to return to work following rehabilitation of whiplash injuries. $J$ Occup Rehabil. 2007;17(2):305-315. doi:10.1007/s10926-007-9082-3

33. Keefe FJ, Abernethy AP, C Campbell L. Psychological approaches to understanding and treating disease-related pain. Annu Rev Psychol. 2005;56:601-630. doi:10.1146/annurev.psych.56.091103.070302

34. Sullivan MJ, Feuerstein M, Gatchel R, Linton SJ, Pransky G. Integrating psychosocial and behavioral interventions to achieve optimal rehabilitation outcomes. J Occup Rehabil. 2005;15(4):475489. doi:10.1007/s10926-005-8029-9

35. Spielberger CD, Gorssuch RL, Lushene PR, Vagg PR, Jacobs GA. Manual for the State-Trait Anxiety Inventory. Palo Alto, CA: Consulting Psychologists Press; 1983.

36. Brandsborg B. Pain following hysterectomy: epidemiological and clinical aspects. Dan Med J. 2012;59(1):4374.

37. Weissman-Fogel I, Granovsky Y, Crispel Y, et al. Enhanced presurgical pain temporal summation response predicts post-thoracotomy pain intensity during the acute postoperative phase. J Pain. 2009;10 (6):628-636. doi:10.1016/j.jpain.2008.12.009

38. Naert AL, Kehlet H, Kupers R. Characterization of a novel model of tonic heat pain stimulation in healthy volunteers. Pain. 2008;138 (1):163-171. doi:10.1016/j.pain.2007.11.018

39. Brandsborg B, Dueholm M, Nikolajsen L, Kehlet H, Jensen TS. A prospective study of risk factors for pain persisting 4 months after hysterectomy. Clin J Pain. 2009;25(4):263-268. doi:10.1097/ AJP.0b013e31819655ca

40. Sullivan M. The Pain Catastrophizing Scale: User Manual. Montreal: McGill University, 2009.

41. Petersen KK, Arendt-Nielsen L, Simonsen O, Wilder-Smith O, Laursen MB. Presurgical assessment of temporal summation of pain predicts the development of chronic postoperative pain 12 months after total knee replacement. Pain. 2015;156(1):55-61. doi:10.1016/j. pain.0000000000000022

42. Gerbershagen HJ, Dagtekin O, Rothe T, et al. Risk factors for acute and chronic postoperative pain in patients with benign and malignant renal disease after nephrectomy. Eur J Pain. 2009;13(8):853-860. doi:10.1016/j.ejpain.2008.10.001

43. Taillefer MC, Carrier M, Belisle S, et al. Prevalence, characteristics, and predictors of chronic nonanginal postoperative pain after a cardiac operation: a cross-sectional study. J Thorac Cardiovasc Surg. 2006;131(6):1274-1280. doi:10.1016/j.jtcvs.2006.02.001

44. Han C, Ge Z, Jiang W, Zhao H, Ma T. Incidence and risk factors of chronic pain following hysterectomy among Southern Jiangsu Chinese Women. BMC Anesthesiol. 2017;17(1):103. doi:10.1186/s12871-017-0394-3

45. Montes A, Roca G, Sabate S, et al. Genetic and clinical factors associated with chronic postsurgical pain after hernia repair, hysterectomy, and thoracotomy: a two-year multicenter cohort study. Anesthesiology. 2015;122(5):1123-1141. doi:10.1097/ALN.000000 0000000611

46. Pokkinen SM, Nieminen K, Yli-Hankala A, Kalliomaki ML. Persistent posthysterectomy pain: a prospective, observational study. Eur J Anaesthesiol. 2015;32(10):718-724. doi:10.1097/EJA.000000 0000000318 
47. Theunissen M, Peters ML, Schepers J, et al. Recovery 3 and 12 months after hysterectomy: epidemiology and predictors of chronic pain, physical functioning, and global surgical recovery. Medicine (Baltimore). 2016;95(26):e3980. doi:10.1097/MD.0000000000003 980
48. Vitale SG, La Rosa VL, Rapisarda AMC, Lagana AS. Impact of endometriosis on quality of life and psychological well-being. $J$ Psychosom Obstet Gynaecol. 2017;38(4):317-319. doi:10.1080/ 0167482X.2016.1244185

\section{Publish your work in this journal}

The Journal of Pain Research is an international, peer reviewed, open access, online journal that welcomes laboratory and clinical findings in the fields of pain research and the prevention and management of pain. Original research, reviews, symposium reports, hypothesis formation and commentaries are all considered for publication. The manuscript management system is completely online and includes a very quick and fair peer-review system, which is all easy to use. Visit http:// www.dovepress.com/testimonials.php to read real quotes from published authors. 